\title{
TEORIA GERAL UNIFICADA DOS CAMPOS FÍSICO, MENTAL E SOCIAL
}

RESUMO: Este estudo introduz uma teoria unificada de amplitude máxima. Seu desenvolvimento repousa sobre o pressuposto fático de que os espaços (campos) físico, mental e social são inseparáveis e só se separam por abstração. Este pressuposto facilita a formulação desta teoria unificada de espaços, ao que parece sem precedente. 5 postulados (ou axiomas) são induzidos da realidade e 23 teoremas são deduzidos dos postulados. Conforme o protocolo científico da rigorosa construção teórica axiomática, nenhum postulado é deduzido de outros postulados e os postulados são necessariamente em pequeno número. Todas as proposições seriam comprovadas ou comprováveis por pesquisa empírica. É de notar que há um máximo de complexidade nos espaços mental e social, sobretudo no espaço social, que é derivação do mental -- daí a redução teórica dos espaços físico, mental e social não ultrapassar um estágio apenas tentativo. A teoria apresentada é determinística e, como tal, não abandona o terreno da probabilidade, no máximo é apenas altamente provável.

Palavras-chave: Campos físico, mental e social. Teoria unificada. Postulados, teoremas. Construção teórica axiomática.
ABSTRACT: This study introduces an unified theory of utmost amplitude. Its development rests on the factual presupposition that the physical, mental and social spaces (fields) are inseparable and are separable only by abstraction. This assumption facilitates the formulation of this apparently without precedent unified theory of spaces. 5 postulates (or axioms) are induced from reality and 23 theorems are deduced from the postulates. According to the scientific protocol of the rigourous theoretical axiomatic construction, no postulate is deduced from other postulates and the postulates are necesssarily in small number. All propositions must be confirmed or may be confirmed by empirical research. One must be aware that there is a maximum of complexity in the mental and social spaces, above all in the social space, which is a derivation from the mental one. The presented theory is deterministic and, as such, does not abandon thev terrain of probability, at the utmost is only highly probable.

Keywords: Physical, mental and social fields. Unified theory. Postulates, theorems. Axiomatic theoretical construction.

\footnotetext{
${ }^{1} \mathrm{Na}$ Universidade Federal de Pernambuco, Doutor, Livre--Docente de Introdução à Ciência do Direito, Professor Titular Emérito de Sociologia do Direito. Antigo Professor Titular fundador de Sociologia do Direito na Universidade Católica de Pernambuco. Lecionou a disciplina "Homem e Ethos" do Mestrado em Filosofia da UFPE. Regeu interinamente a então cátedra Direito Constitucional da Faculdade de Direito do Recife. Doutor em Ciências Sociais (Dr. rer. soc.\} pela Faculdade de Sociologia da Universidade de Bielefeld (Alemanha), havendo defendido tese sobre Teoria Sociológica Geral intitulada Fundamentos Científicos mais gerais do Social (Allgemeinste wissenschaftliche Grundlagen des Sozialen). Antigo Pesquisador-Chefe da Universidade Federal de Pernambuco, Pesquisador 1A do Conselho Nacional de Desenvolvimento Científico e Tecnológico (CNPq) e consultor desse órgão. Pesquisador Fulbright nos Estados Unidos, onde foi "Visiting Research Fellow" do "Southwestern Legal Center" (Dallas) e "Visiting Research Scholar" das "Graduate Faculties" da Universidade de Columbia (New York). Professor Visitante da Universidade de Colônia (Köln, Alemanha), em programa da Fundação Alexander von Humboldt. Professor Visitante do Centro de Pesquisa Interdisciplinar ("Zentrum für interdisziplinäre Forschung") da Universidade de Bielefeld. Inúmeras publicações no país e no exterior.
} 


\section{INTRODUÇÃO}

Exponho aqui os elementos constituintes de minha teoria geral unificada dos campos físico, mental e social. Assim, justifico a estrutura e ausência de citações porque as ideias estão desenvolvidas em seus detalhes em minhas obras, como se pode observar nas referências.

Após apresentar os cinco postulados da teoria, faço esclarecimentos, para então expor os 23 teoremas que me levam à referida teoria.

\section{POSTULADOS}

1. Nos espaços (campos) físico, mental e social, quanto mais energia e menos distância, mais atração.

2. Nos espaços físico, mental e social, a atração varia na razão direta da afinidade e inversa da distância.

3. Nos espaços físico, mental e social, quanto menos distância, mais atração e repulsão. A atração guarda mais energia do que a repulsão.

4. Nos espaços físico, mental e social, já que esses campos não se separam senão por abstração, o equilíbrio em cada um desses campos sempre causa equilíbrio nos outros dois campos, e o desequilíbrio em cada um desses campos sempre causa desequilíbrio nos outros dois campos.

5. Nos espaços físico, mental e social, quanto maior a ideia de semelhança, maior a agradabilidade, e o sentimento de agradabilidade, ou de preponderante agradabilidade diante de algo, sempre causa, respectivamente, aproximação, ou uma resultante de aproximação, em direção a esse algo, com emissão da energia de ondas mentais equilibrantes (coesivas, integrativas).

-- Inversamente, quanto maior a ideia de dessemelhança, maior a desagradabilidade, e o sentimento de desagradabilidade ou de preponderante desagradabilidade diante de algo sempre causa, respectivamente, afastamento, ou uma 
resultante de afastamento, quanto a esse algo, com emissão da energia de ondas mentais desequilibrantes (descoesivas, desintegrativas).--

\section{ESCLARECIMENTOS}

Quanto ao segundo postulado, não temos ainda dados científicos sobre a velocidade do pensamento humano, presumivelmente maior que a da luz, dados esses que possibilitariam quantificação satisfatória da proposição unificada. Note-se ainda que a afinidade é objeto de estudo da Química e da Física, e não apenas das ciências humanas.

Premissa geral de natureza científica deste estudo - não há separação real dos campos físico, mental e social, o que facilita uma teoria unificada desses campos. $\underline{A}$ separação que se faz é mera abstração, não é realidade. E aproxima-se do óbvio a ideia da interação constante entre a natureza e o homem. E a natureza é o espaço ambiental onde ocorre o mental e o social humano interativos com a natureza.

Repare-se que a natureza, terrena ou já primordialmente cósmica, ou seja, o espaço (campo) físico, está no homem e no seu exterior, formando seu ambiente. A abrangência espacial é magnífica, pois já é inicialmente cósmica.

Os espaços físico, mental e social apresentam uma complexidade progressiva, a partir do espaço físico, havendo um máximo de complexidade nos espaços mental e social, sobretudo no social, que é uma derivação do mental. Daí a redução teórica geral unificada desses espaços não ultrapassar um estágio apenas tentativo. Note-se que nem na Física, de objeto menos complexo, se conseguiu uma teoria unificada dos seus campos.

Assim, na presente construção teórica, o postulado 5 apresenta o máximo de complexidade. Nesse postulado, o mental é representado por ideia e por sentimento, ficando implícita a vontade, motor da ação.

A ciência atual se orienta pela humildade. A Física, a ciência humana mais desenvolvida, se afirma indeterminada, inexata, incerta, mesmo em suas proposições determinísticas, estas apenas altamente prováveis.

Repare-se que a alta probabilidade em ciência (mesmo na construção determinística da Física) paga o preço da aproximação da evidência. Como na clássica lei da gravitação universal de Newton: no fundo se tenderia ao óbvio de que quanto mais 
massa e menos distância mais atração. Ou como na importante equação da energia de Einstein, na qual permanece a tendência ao óbvio, pois a energia variaria na razão direta da massa e da velocidade.

Neste artigo são deduzidos dos postulados 23 teoremas. Outros teoremas são dedutíveis.

Sabe-se que a atividade científica teórica alcança seu nível máximo de rigor na construção axiomática. A palavra "sempre", implícita ou explícita, na construção de postulados determinísticos, significa apenas um alto grau de probabilidade.

Os axiomas ou postulados são obtidos por indução do particular concreto e deles se podem deduzir proposições menos gerais, os teoremas, que seriam explicados pelos postulados.

\section{TEOREMAS}

1. (Ceteris paribus), nos espaços físico, mental e social, quanto menos espaço, menos tempo; e, quanto mais espaço, mais tempo.

2. Nos espaços físico mental e social, quanto maior a ideia de semelhança no sistema interativo (e consequentemente quanto maior a agradabilidade do sentimento), tanto mais rapidamente a passagem do tempo será experimentada.

3. Havendo força de repulsão entre polos interativos nos espaços físico, mental e social, quanto maior a distância entre esses polos, menor a força repulsiva entre eles.

4. Havendo força de atração entre polos interativos nos espaços físico, mental e social, quanto menor a distância entre esses polos, maior a força atrativa entre eles.

5. Nos espaços físico, mental e social, (ceteris paribus) se há agradabilidade do sentimento (correspondente a aproximação), a eventual intensidade emocional é menor, com menor dissipação de energia, do que se há desagradabilidade do sentimento (correspondente a afastamento).

6. Nos espaços físico, mental e social, se há equilíbrio permanente do sistema interativo, o processo resultante é associativo (integrativo). 
7. Nos espaços físico, mental e social, quanto maior a semelhança entre os polos interativos (tal como definida em função do que aceitam), tanto maior o equilíbrio do sistema interativo.

8. Nos espaços físico, mental e social, quanto menor a distância entre polos interagentes, tanto maior é o índice relativo de interação entre eles (a relatividade do índice de interação é referente ao número dos polos interagentes, e esse índice é da frequência e duração do processo interativo).

9. Nos espaços físico, mental e social, se a ideia de semelhança é maior do que a necessária para o equilíbrio permanente do sistema interativo, o processo resultante é da maior agradabilidade (=maior suavidade afetiva=paz).

10. Nos espaços físico, mental e social, quanto maior a paz do sistema interativo, maior o equilíbrio desse sistema.

11. Nos espaços físico, mental e social, quanto maior a padronização (uniformização) do elemento ideia de polos interativos, tanto maior a semelhança entre esses polos e consequentemente tanto maior o equilíbrio do sistema correspondente de interação.

12. Nos espaços físico, mental e social, se polos interativos têm seu elemento "ideia" padronizado de maneira científico-empírica, nessa medida há a máxima possibilidade de convicção de que esse elemento "ideia" corresponda à realidade e, portanto, a máxima possibilidade de padronização de tal elemento "ideia"; consequentemente, há a máxima possibilidade de equilíbrio do sistema correspondente de interação (=máxima possibilidade de paz).

13. Nos espaços físico, mental e social, se polos interagentes têm o seu elemento "ideia" padronizado, inclusive científico-empiricamente, na extensão dessa padronização, o elemento "sentimento", no sentido geral do sentimento de agradabilidade, é o fator principal da mudança (alteração menor ou maior) do sistema interativo correspondente (e não já o elemento "ideia”, que, nessa extensão, pode ser considerado uma constante).

14. Nos espaços físico, mental e social, quanto maior o equilíbrio do sistema interativo, tanto mais prontamente ele controla qualquer acontecimento que possa perturbar a integração do sistema. 
15. Nos espaços físico, mental e social, quanto menor a distância entre polos interativos, tanto menos energia será necessária para comunicação e controle.

16. Nos espaços físico, mental e social, na interação da paz, há o mínimo de energia necessária para comunicação e controle.

17. Nos espaços físico, mental e social, a mudança é uma constante, sendo que quanto maior a ideia de semelhança entre polos interativos, tanto maior o equilíbrio do sistema respectivo de interatos e tanto menos linguagem material (linguagem condensada em signos materiais) é necessária para a comunicação e controle - seja esta comunicação dialogal interna (diálogo mental do indivíduo consigo mesmo), ou exteriorizada.

18. Nos espaços físico, mental e social, quanto mais a socialização (exposição a padrões sociais) se faça no sentido da semelhança entre polos interativos, tanto maior o equilíbrio do sistema de interatos correspondente a tais polos.

19. Nos espaços físico, mental e social, quanto mais a socialização se faça no sentido da semelhança entre polos interativos, tanto mais paz.

20. Nos espaços físico, mental e social, na medida em que a socialização se faça em termos de dessemelhança entre polos interativos, nessa medida os polos assim socializados tenderão a conduta desequilibrante do sistema interativo.

21. Nos espaços físico, mental e social, quanto maior o afastamento pela ideia de dessemelhança, maior a desagradabilidade. E quanto maior a desagradabilidade, tanto maior a tendência para o conflito (conflito mental: conflito interno, ou conflito externo: luta).

22. Nos espaços físico, mental e social, na aproximação pela ideia de semelhança, quanto maior a aproximação, maior a agradabilidade, e, quanto maior esta última, maior a tendência, para a cooperação e a paz, com maior estabilidade da integração. E quanto maior a competição ("luta pacífica", processo de afastamento nos espaços mental e social), maior a instabilidade da integração mental e social.

23. Nos espaços físico, mental e social, (definida cientificamente a justiça como sentimento de agradabilidade diante do que se acha que deve ser,) se um sistema de interatos é considerado essencialmente (principalmente) justo por um ou mais polos interativos (e portanto essencialmente semelhante ao que eles aceitam), tais polos 
experimentam uma situação de relativa e saudável suavidade afetiva. Caso contrário, as situações oscilantes de agradabilidade e desagradabilidade, sobretudo as de desagradabilidade, desde que não são situações relativamente suaves, favorecem condições patológicas desequilibrantes no indivíduo e consequentemente no sistema interativo de que se trate.

\section{REFERÊNCIAS}

EINSTEIN, Albert. Ideas and Opinions. New York/Avenel, New Jersey: Wings Books, 1954.

NEWTON, Sir Isaac. Mathematical Principles of Natural Philosophy. Translated by Andrew Motte and revised by Florian Cajori. Chicago-London-Toronto: William Benton, Publisher, Encyclopaedia Britannica, Inc., 1955.

SOUTO, Cláudio. Allgemeinste wissenschaftliche Grundlagen des Sozialen. Wiesbaden: Franz Steiner Verlag, 1984.

SOUTO, Cláudio. Axiomatic Reason in Sociology and in Sociology of Law. In: Carla Faralli and Enrico Pattaro (Eds.). Reason in Law, Proceedings of the Conference held in Bologna, 12-15 December 1984, v. III. Milano: Dott. A. Giuffrè Editore, 1988.

SOUTO, Cláudio. Probabilidade, Condição e Causalidade: Comparando as Distâncias Física, Mental e Social. Revista Brasileira de Filosofia, v. LII, Fasc. 208, out./nov./dez. 2002.

SOUTO, Cláudio. Teoria Sociológica Geral: uma fundamentação mais abrangente. 2. ed. rev. e aum. São Paulo: E.P.U., 2006.

SOUTO, Cláudio. Natureza, Mente e Direito: para além do usual acadêmico. 3. ed. rev. Porto Alegre: Sergio Antonio Fabris Editor, 2015. 